\title{
Strategies to Prolong Ketamine's Efficacy in Adults with Treatment-Resistant Depression
}

\author{
Eric P. McMullen · Yena Lee · Orly Lipsitz • Leanna M. W. Lui • \\ Maj Vinberg · Roger Ho · Nelson B. Rodrigues · Joshua D. Rosenblat • \\ Bing Cao · Hartej Gill · Kayla M. Teopiz • Danielle S. Cha • \\ Roger S. McIntyre
}

Received: February 18, 2021 / Accepted: March 25, 2021 / Published online: April 30, 2021

(c) The Author(s) 2021

\section{ABSTRACT}

Introduction: Ketamine treatment is capable of significant and rapid symptom improvement in adults with treatment-resistant depression (TRD). A limitation of ketamine treatment in TRD is the relatively short duration of time to relapse (e.g., median 2-4 weeks). The objective of the systematic review herein is to identify strategies capable of prolonging the acute efficacy of ketamine in adults with TRD.

E. P. McMullen · Y. Lee · O. Lipsitz ·

L. M. W. Lui - N. B. Rodrigues · J. D. Rosenblat .

H. Gill · K. M. Teopiz - D. S. Cha · R. S. McIntyre $(\square)$

Mood Disorder Psychopharmacology Unit,

University Health Network, University of Toronto, 399 Bathurst Street, MP 9-325, Toronto, ON M5T

2S8, Canada

e-mail: roger.mcintyre@uhn.ca

E. P. McMullen · Y. Lee · O. Lipsitz ·

L. M. W. Lui · N. B. Rodrigues · J. D. Rosenblat .

H. Gill · D. S. Cha · R. S. McIntyre

Canadian Rapid Treatment Center of Excellence,

Mississauga, ON, Canada

\section{R. S. McIntyre}

Brain and Cognition Discovery Foundation, Canada, University of Toronto, Toronto, ON, Canada

R. Ho

Institute for Health Innovation and Technology
Methods: PubMed/MEDLINE databases were searched from inception to December 2020 for clinical studies written in English using the following key terms: ketamine, prolong, and depression. A total of 454 articles were identified from the literature search which included all clinical studies regarding prolonging the antidepressant effects of ketamine. Twenty-two articles were included: ten randomized controlled trials (RCTs), eight prospective open-label trials, one retrospective chart review, and three case reports. The Preferred Reporting Items for Systematic Reviews and Meta-Analyses

(iHealthtech), National University of Singapore, Singapore, Singapore

\section{R. Ho}

Department of Psychological Medicine, National University Hospital, Singapore, Singapore

B. Cao

Key Laboratory of Cognition and Personality, Faculty of Psychology, Ministry of Education, Southwest University, Chongqing 400715, People's Republic of China

\section{Vinberg}

Faculty of Health and Medical Sciences, Department of Clinical Medicine, Psychiatric Research Unit, University of Copenhagen, Psychiatric Centre North Zealand, Hilleroed, Denmark 
(PRISMA) guidelines were used for data extraction. The primary outcome was prolonged effect, defined as statistically significant antidepressant effects following acute ketamine treatment.

Results: A total of 454 articles were identified, and 22 articles were included. Different treatment modalites including pharmacological interventions, manualized-based psychotherapies, electroconvulsive therapy, transcranial magnetic stimulation, and intravenous monotherapy were examined to determine their impact on the prolongation of antidepressant effects following acute ketamine treatment. No treatment modality, other than repeat-dose IV ketamine, has demonstrated ability to significantly prolong the acute efficacy of IV ketamine in TRD.

Conclusion: Hitherto, available open-label data and controlled trial data support repeat administration of IV ketamine as an effective strategy to prolong the efficacy of ketamine's antidepressant effects (although not the focus of the study herein, maintenance repeat-dose esketamine treatment is proven effective in esketamine responders). There is a need to identify multimodality strategies that are safe and capable of prolonging the efficacy of ketamine in adults with TRD.

Keywords: Anxiety; Bipolar disorder; Depression; Esketamine; Ketamine; Major depressive disorder; Suicidality; Treatmentresistant depression

\section{Key Summary Points}

Up to $40 \%$ of patients with major depressive disorder fail to achieve syndromal and functional recovery with conventional monoamine-based antidepressants. Prolonging the rapid significant antidepressants effects of IV ketamine in persons with treatment resistant depression is a priority research vista. Esketamine has demonstrated both acute and maintenance efficacy in adults with treatment resistant depression.
We explored strategies to prolonging ketamine's efficacy in adults with treatment-resistant depression.

We identified 454 articles within our literature search and included 22 articles for data extraction.

No modality of treatment has demonstrated ability to sufficiently prolong the acute efficacy of ketamine in treatment resistant depression; however, some modalities of treatment showed promising results.

There remains a need to identify multimodality strategies that are safe and capable of prolonging efficacy of ketamine.

\section{DIGITAL FEATURES}

This article is published with digital features, including a summary slide, to facilitate understanding of the article. To view digital features for this article go to https://doi.org/10.6084/ m9.figshare.14291405.

\section{INTRODUCTION}

Major depressive disorder (MDD) is a common mental disorder that causes severe functional impairment affecting approximately $10-20 \%$ of individuals at some time in their life [1]. Notwithstanding the availability of disparate psychopharmacological and psychological therapies for treating MDD, up to $40 \%$ of patients fail to achieve syndromal and functional recovery $[2,3]$. For example, the Sequenced Treatment Alternatives to Relieve Depression $\left(\mathrm{STAR}^{*} \mathrm{D}\right)$ study reported that approximately half of patients with MDD failed to achieve remission of depressive symptoms following two sequential courses of conventional treatment [4]. In addition to suboptimal acute treatment outcomes in MDD, monoamine-based treatments require 2-3 weeks before a clinically significant effect may be 
observed $[5,6]$. The foregoing therapeutic inertia contributes to ongoing disability, psychological dysfunction and risk for suicide $[3,5]$.

During the past two decades, the rapid antidepressant effects of ketamine have been reported in adults with treatment-resistant depression (TRD) [7]. Racemic ketamine, as well as esketamine, have demonstrated significant and rapid symptom improvement as well as anti-suicidality effects in adults with TRD [8-10]. Notwithstanding the efficacy of ketamine in adults with TRD, a major limitation is the relatively short duration to relapse (e.g., median 2-4 weeks) [11].

Multiple clinical studies have reported the maintenance antidepressant effects of repeat sub-anesthetic dose intravenous (IV) ketamine for up to 6 weeks, with replicated large effect sizes [9, 12-14]. Compared to conventional antidepressants, IV ketamine is differentiated by (1) efficacy in patients with TRD, (2) a relatively rapid onset of therapeutic effect, and (3) preliminary evidence for reducing suicidality $[10,15]$. From a tolerability and safety perspective, an additional, albeit not treatment-limiting concern with ketamine is the potential for dissociation, as well as vasopressor effects [16-18]. Evaluating the long-term effectiveness of ketamine is limited by a dearth of long-term controlled trial data $[13,19]$.

The objective of this systematic review is to identify strategies that are capable of prolonging efficacy of IV ketamine in adults with TRD. The focus is on IV racemic ketamine rather than esketamine, as esketamine has demonstrated maintenance of efficacy as part of a randomized controlled trial (RCT) wherein repeat-dose esketamine was associated with a prolonged time to relapse when compared to placebo. Thus, the best evidence for prolonging the efficacy of esketamine is to continue repeat-dose esketamine [20].

Herein, we focused on identifying strategies that prolong the antidepressant effects of IV ketamine in adults with TRD. Further, we specifically study the possible synergistic effects and evaluate evidence for (1) prolonged ketamine antidepressant effect combined with psychopharmacological continuation therapy, (2) prolonged ketamine antidepressant effect combined with a psychological therapy, and (3) efficacy of repeated IV ketamine treatment.

\section{METHODS}

Our search adhered to the Preferred Reporting Items for Systematic Reviews and Meta-Analyses (PRISMA) guidelines and examined ways of prolonging the antidepressant effect of ketamine in patients with TRD.

Studies were identified by searching PubMed/MEDLINE from inception to December 2020 for clinical studies (e.g., case reports, chart reviews, clinical trials). Included studies discussed methods of prolonging the antidepressant effects of IV ketamine administration in individuals with TRD. The following search terms were used: ((ketamine OR esketamine OR s-ketamine OR r-ketamine) AND (treatment-resistant depress* OR TRD OR resistant OR treatment refract* depress* OR MDD OR depress* OR major depress*) AND (prolong* OR continu* OR repeat* OR maintenance OR sustain*)). "Prolonged effects" were defined as statistically significant $(P<0.05)$ antidepressant effects following acute IV ketamine treatment known to last up to 7 days [21] and "repeated IV ketamine treatment" defined as more than one instance of IV ketamine treatment beyond acute treatment. All studies were written in English and were conducted in human subjects. Further relevant articles were identified manually through a search of article reference lists. Different studies within this systematic review were compared across a variety of categories including antidepressant effects, safety and tolerability, and limitations. As a result of differences in treatment design, dosage, and treatment frequency, the statistical power of this systematic review remains limited.

This article is based on previously conducted studies and does not contain any studies with human participants or animals performed by any of the authors. 


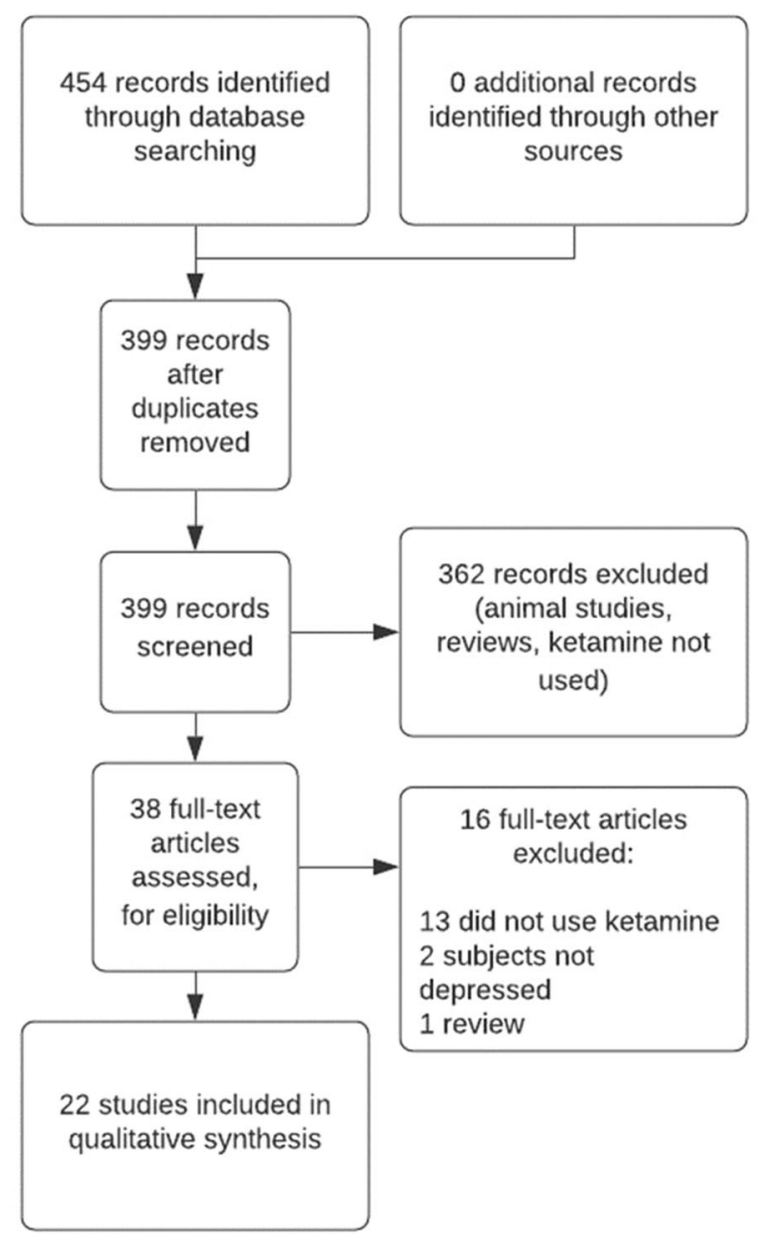

Fig. 1 Flowchart outlining the systematic literature research using PubMed/MEDLINE

\section{RESULTS}

\section{Search Results}

The initial search yielded 454 records in PubMed/MEDLINE, and 399 records after the removal of duplicates (Fig. 1). After title and abstract screening, 362 records were excluded and 37 full-text articles were assessed for eligibility. We included 22 articles in this review: 10 RCTs, 8 prospective open-label trials, 1 retrospective chart review, and 3 case reports (1-28 cases per article). A summary of the 18 prospective studies and 4 retrospective studies (i.e., case reports, chart reviews) can be found in Tables 1 and 2, respectively.

\section{Prospective Studies Assessing Prolonging Ketamine's Antidepressant Effects in MDD}

A total of ten RCTs and eight open-label trials (Table 1) were identified that assessed the extension of racemic IV ketamine's antidepressant effect using a pharmacological intervention (i.e., clonidine, D-cycloserine, lamotrigine, lithium, rapamycin, riluzole; $k=5$ ), psychotherapy (i.e., cognitive behavioral therapy [CBT]; $k=1$ ), electroconvulsive therapy (ECT) $(k=1)$, or IV ketamine monotherapy $(k=9)$. The majority of prospective studies (12/18) included repeat ketamine infusions $[12,13,22-25,27-32]$.

Of the six studies involving oral agents concurrent with ketamine (pooled $n=177$ ), all studies, except one, reported no statistically significant effect of the adjunct intervention compared to ketamine alone. The exception was a RCT completed by Abdallah et al. [33], where a single dose of rapamycin $(6 \mathrm{mg})$ prior to a single dose of IV ketamine showed significantly higher response and remission rates after 2 weeks. Between the rapamycin and placebo trail completers, higher response rates (41\%) and remission rates (29\%) were reported in the preinfusion rapamycin treatment group compared to the response rates (13\%) and remission rates $(7 \%)$ in the placebo arm $(P=0.04$, $P=0.003$ respectively).

In a 32-day RCT $(n=26)$ by Mathew et al. [34], daily riluzole continuation (100-$200 \mathrm{mg}$ /day) did not significantly prolong postketamine relapse after 1 month [34]. Time-torelapse was the primary outcome measure. During the 32-day trial, riluzole did not demonstrate a significant difference in time-torelapse compared to the placebo group, who only received $0.5 \mathrm{mg} / \mathrm{kg}$ IV ketamine and a placebo add-on (24.4 days vs 22.0 days; $P=0.68$ ), with a relapse rate of $80 \%$ vs $50 \%$ for the riluzole and placebo trial completers, respectively. As a result of the foregoing relapse rates, the RCT was terminated prematurely [34]. Furthermore, no significant improvements were found in Montgomery-Asberg Depression Rating Scale (MADRS) scores post-ketamine treatment $(P=0.36)$ [34]. 


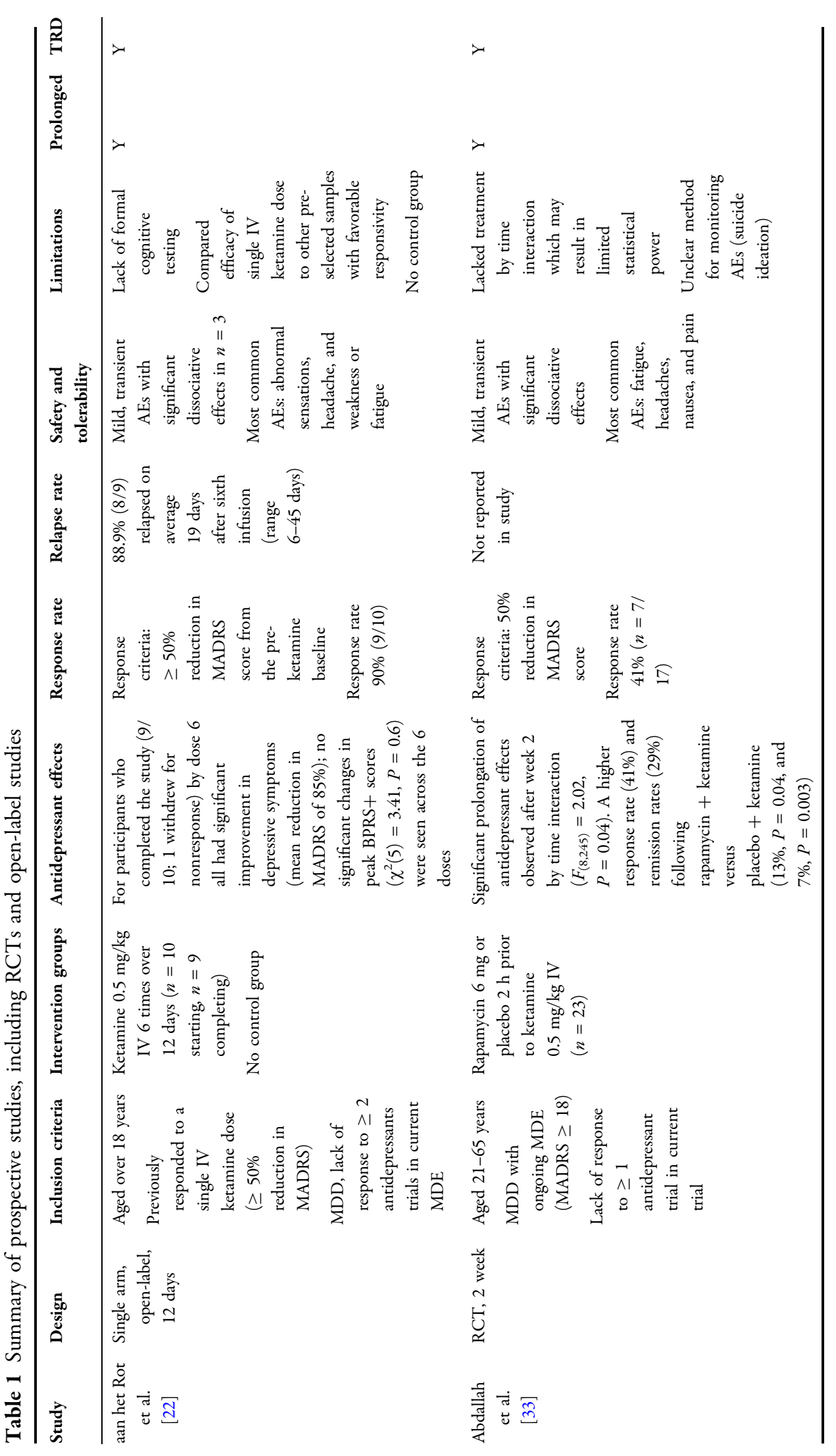




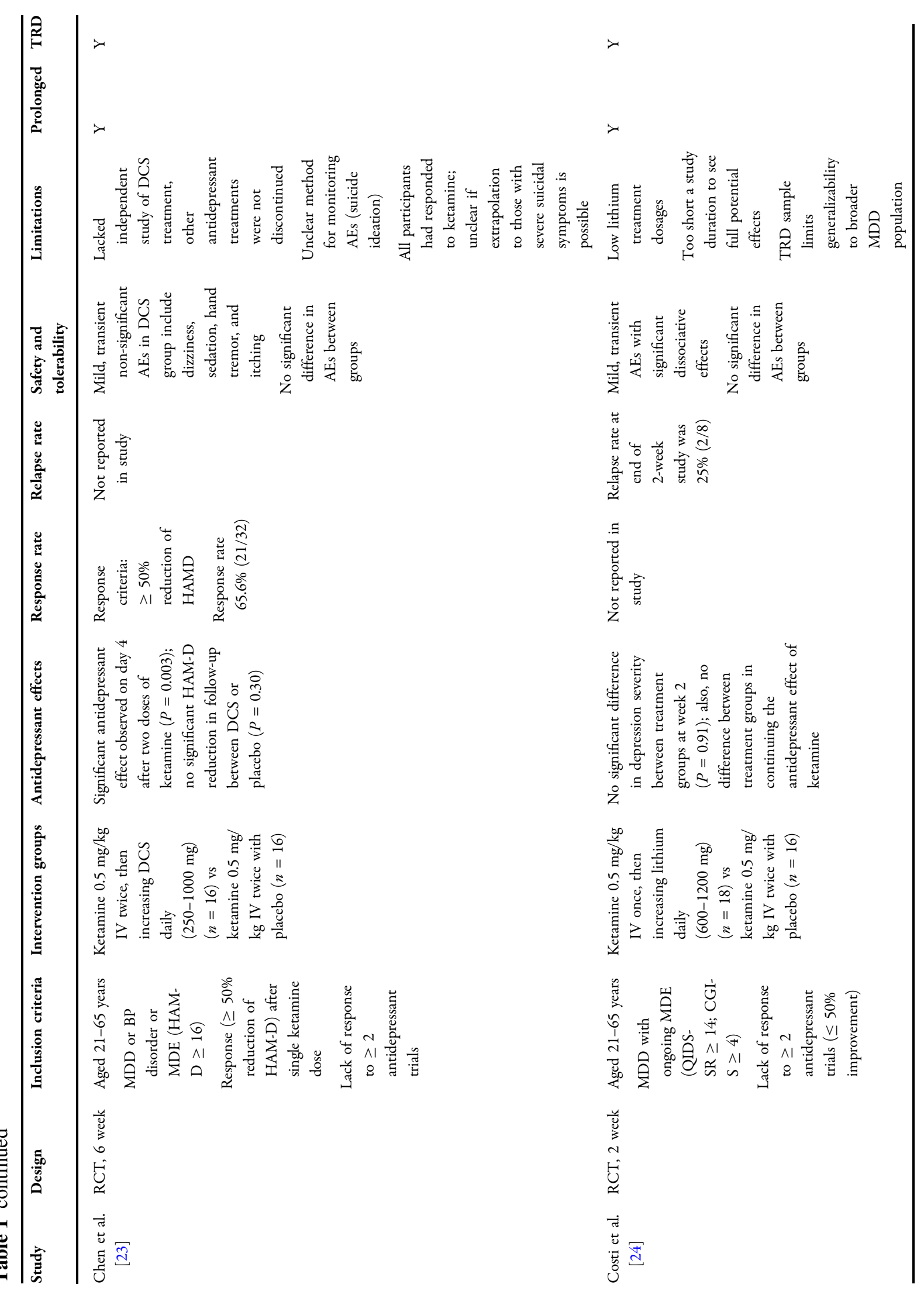




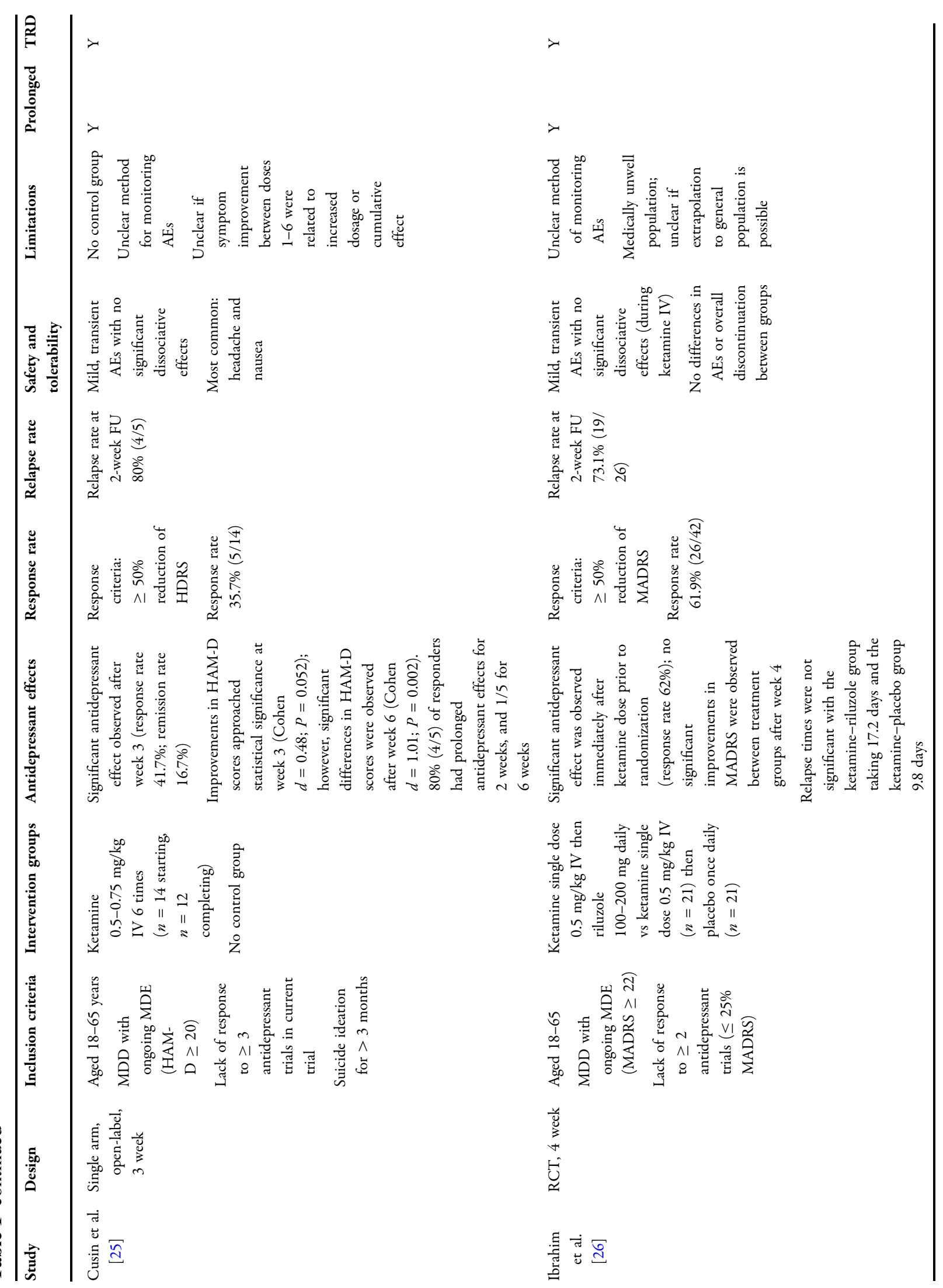




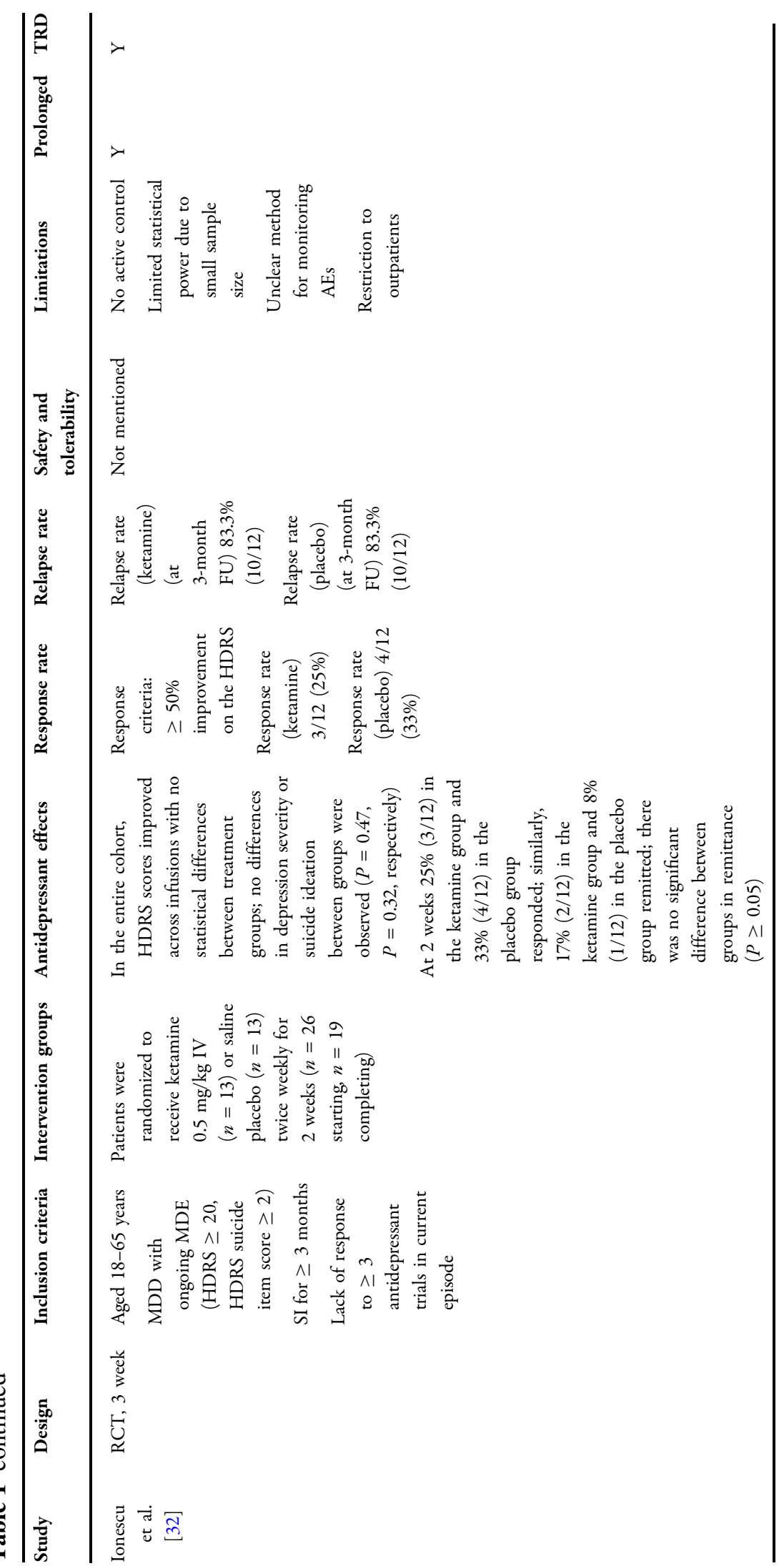




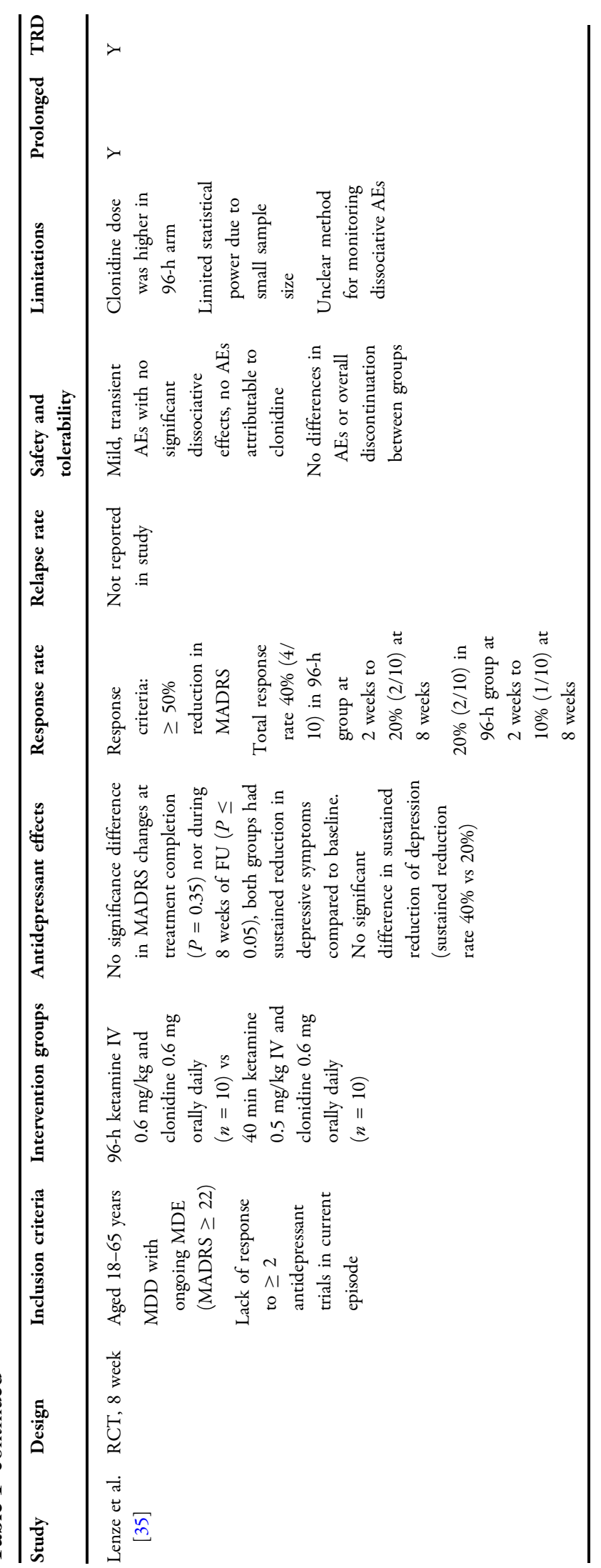




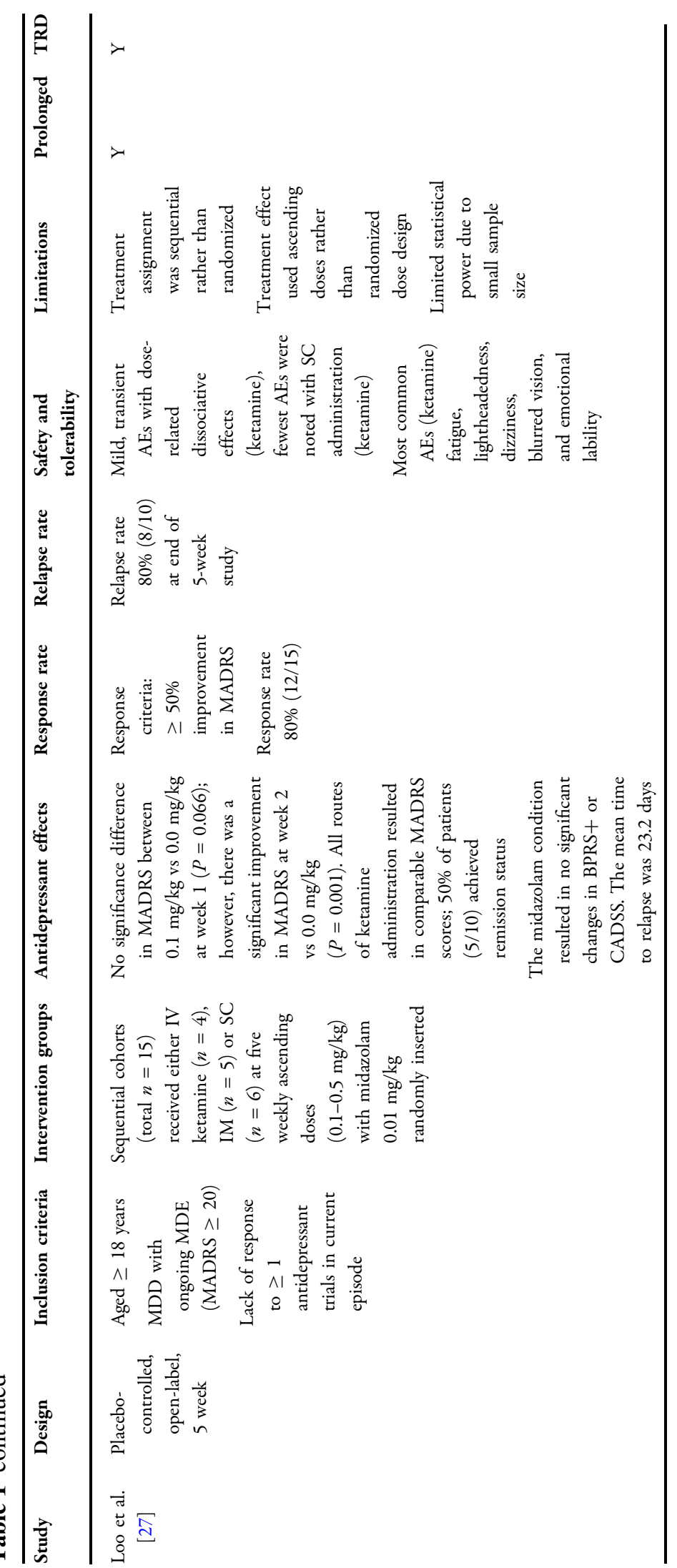




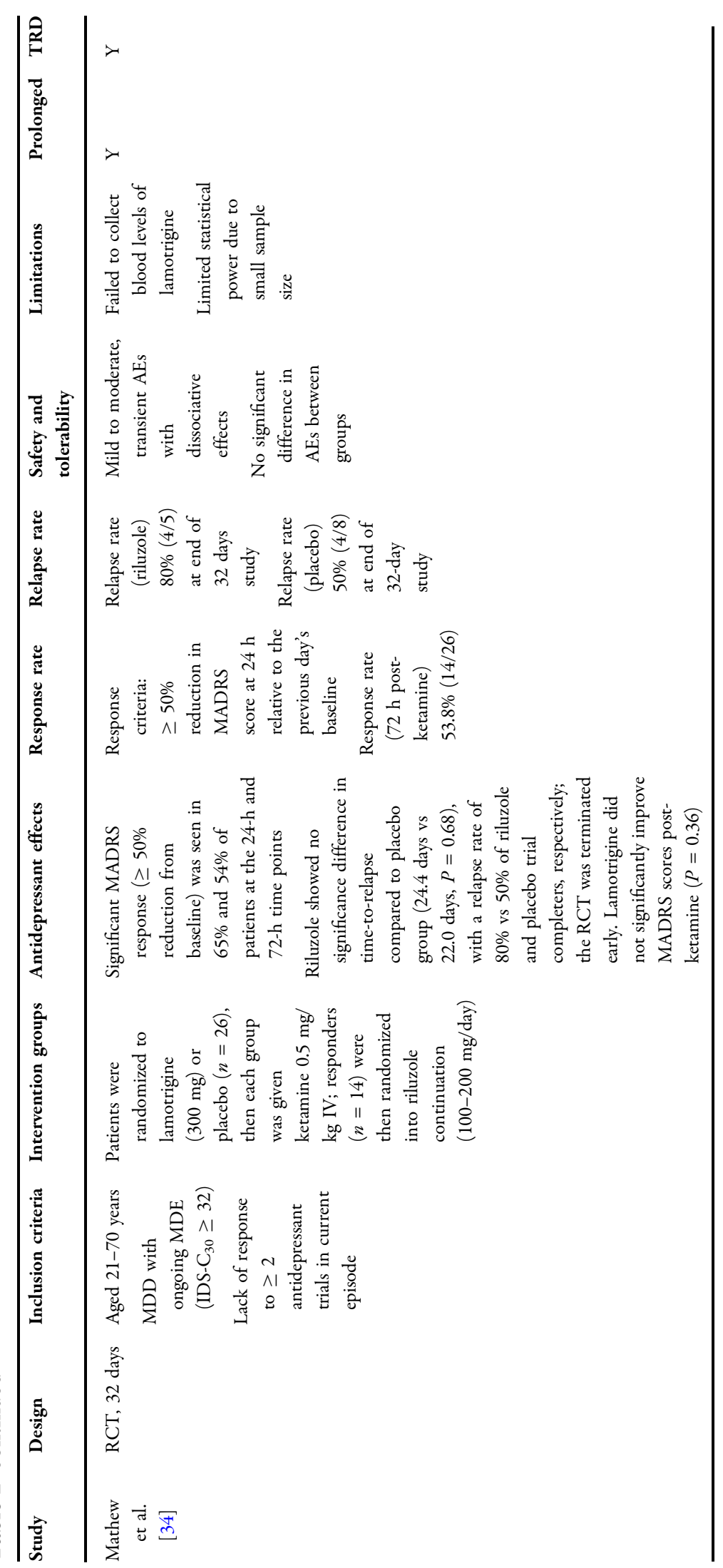




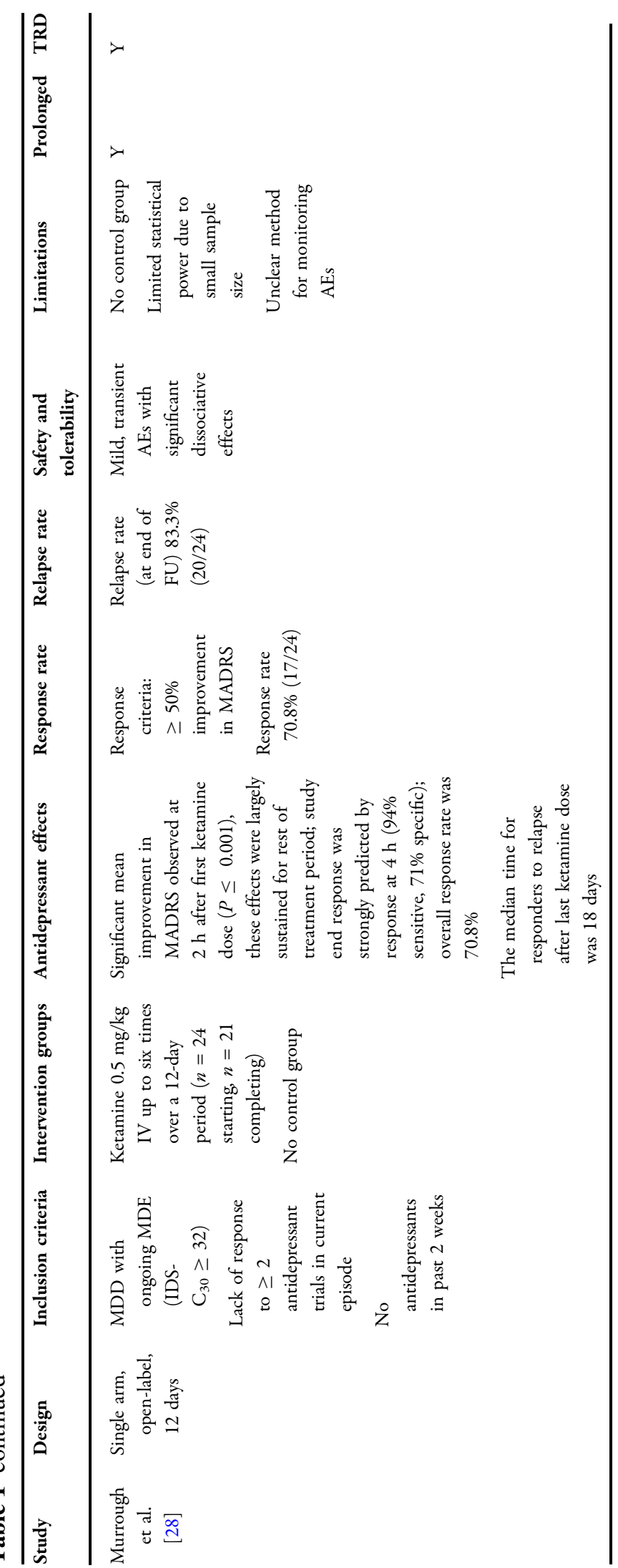




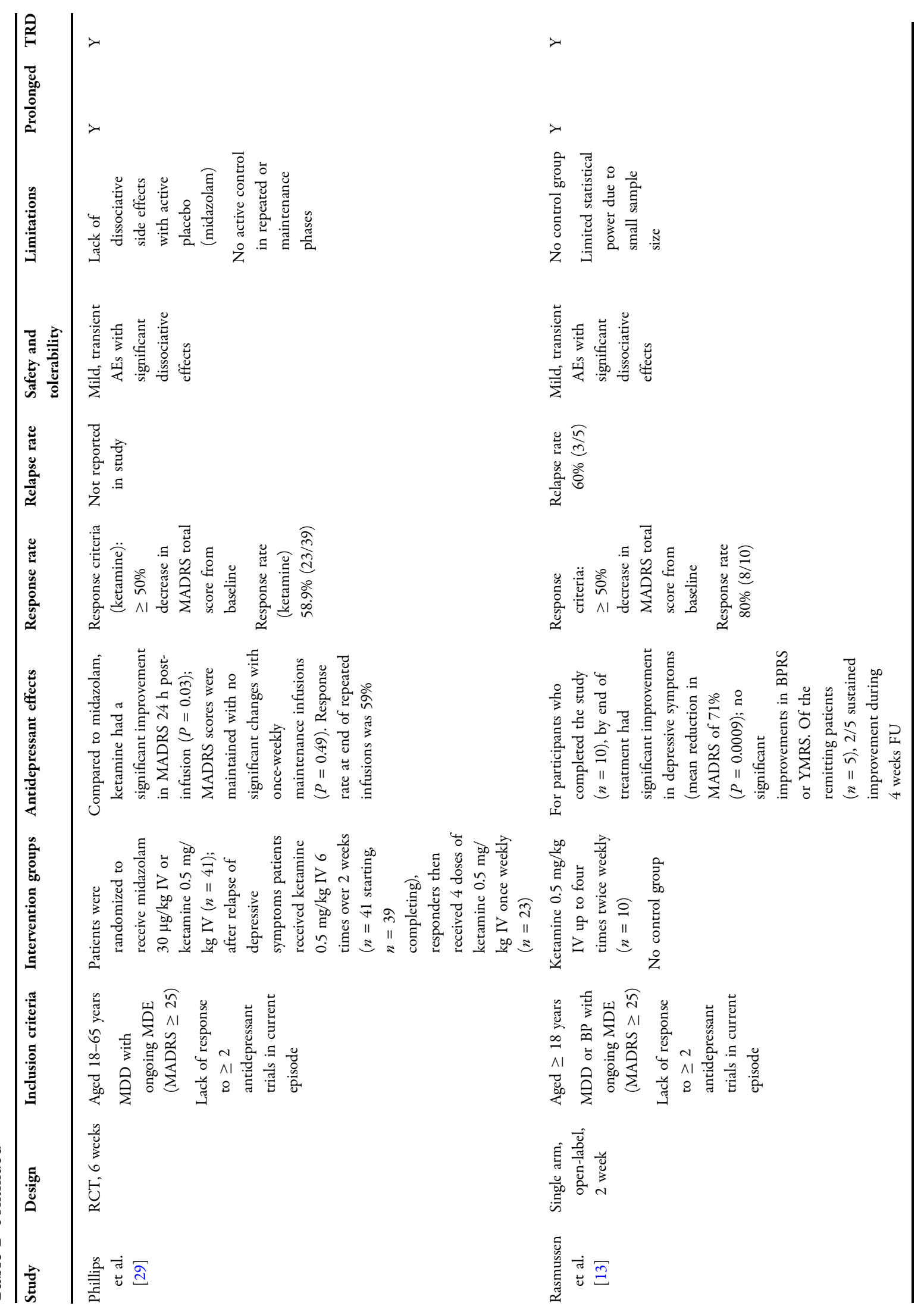




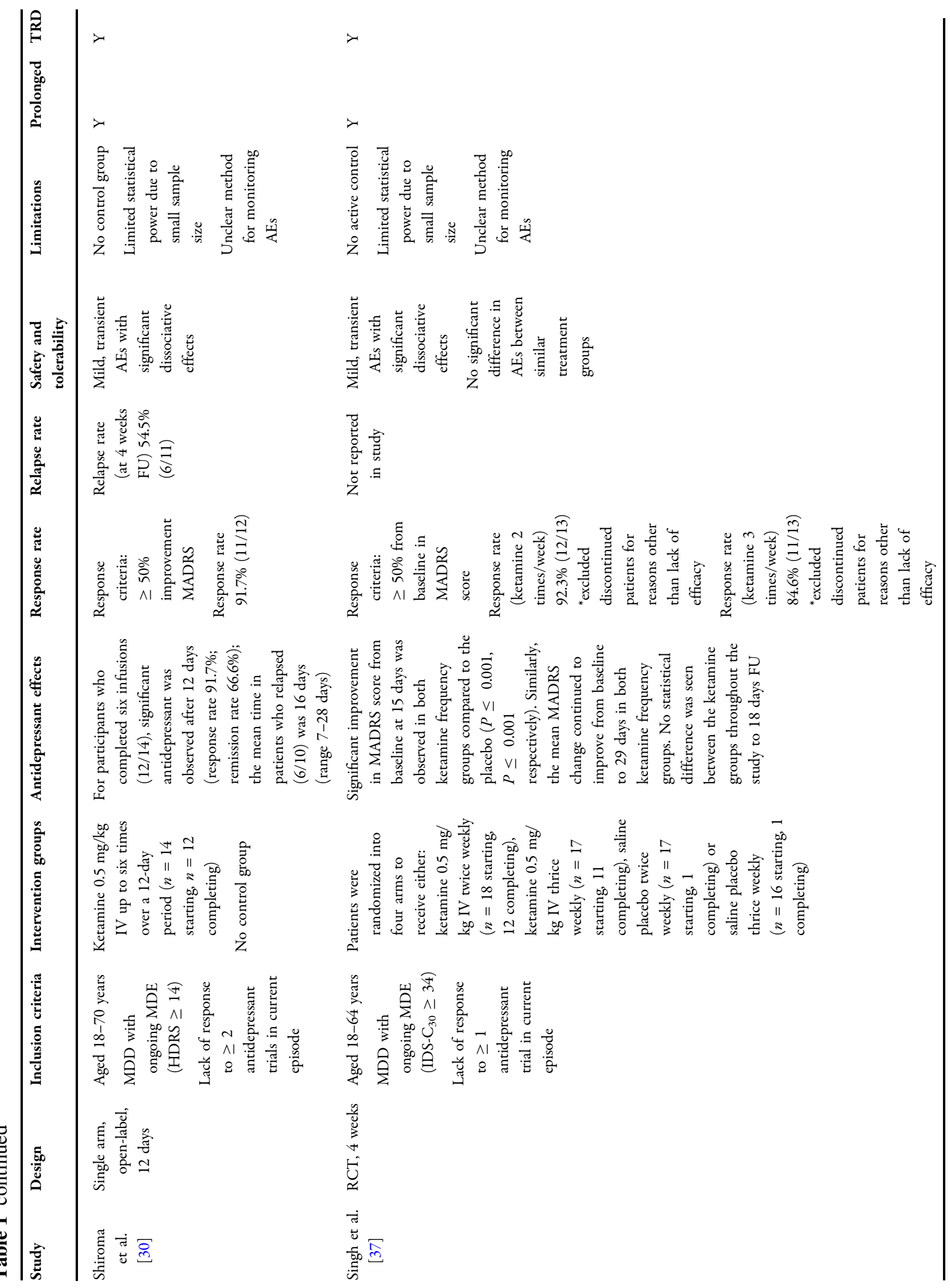




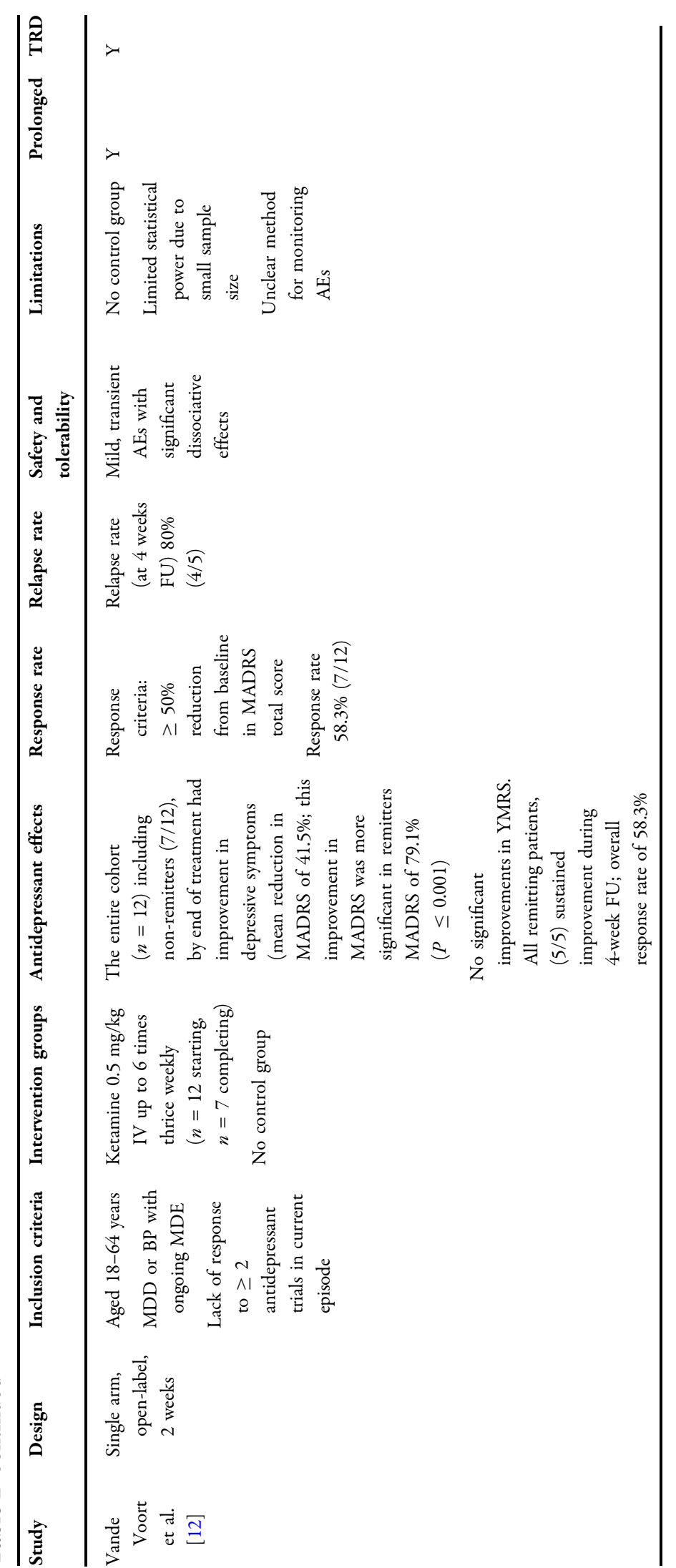




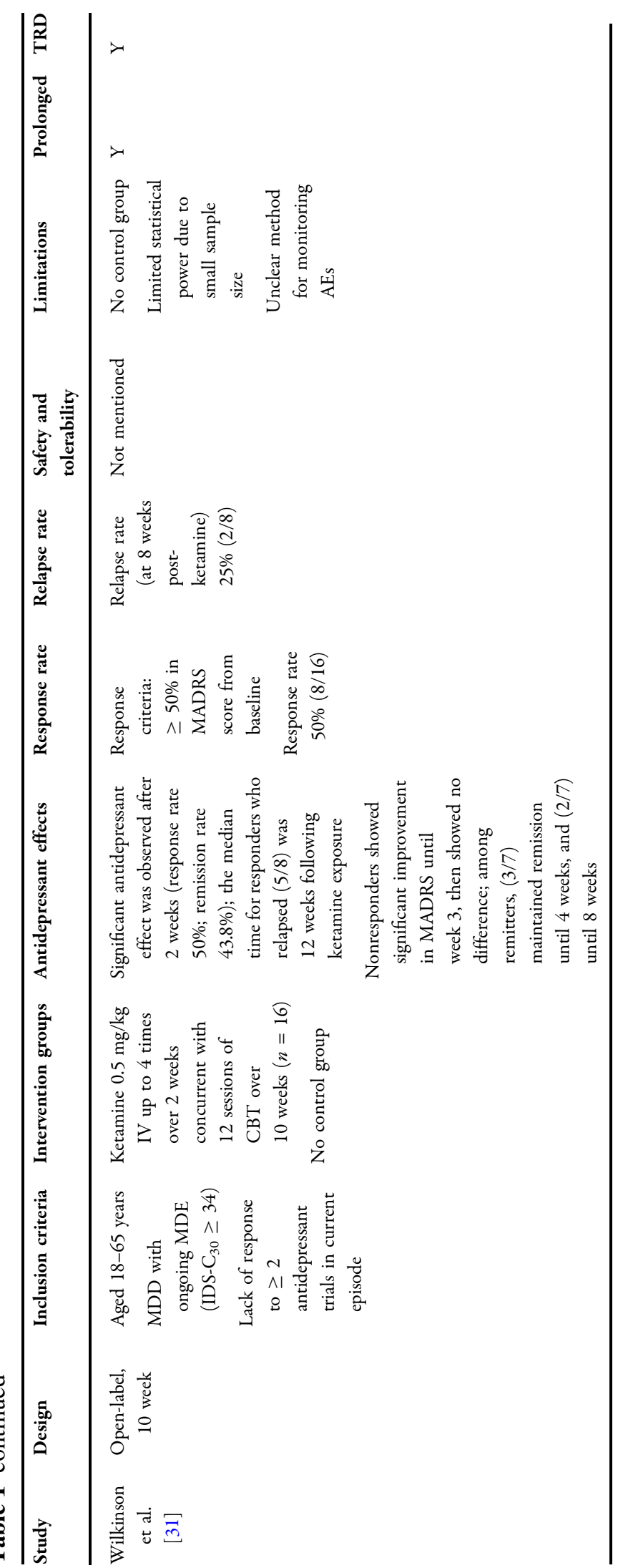




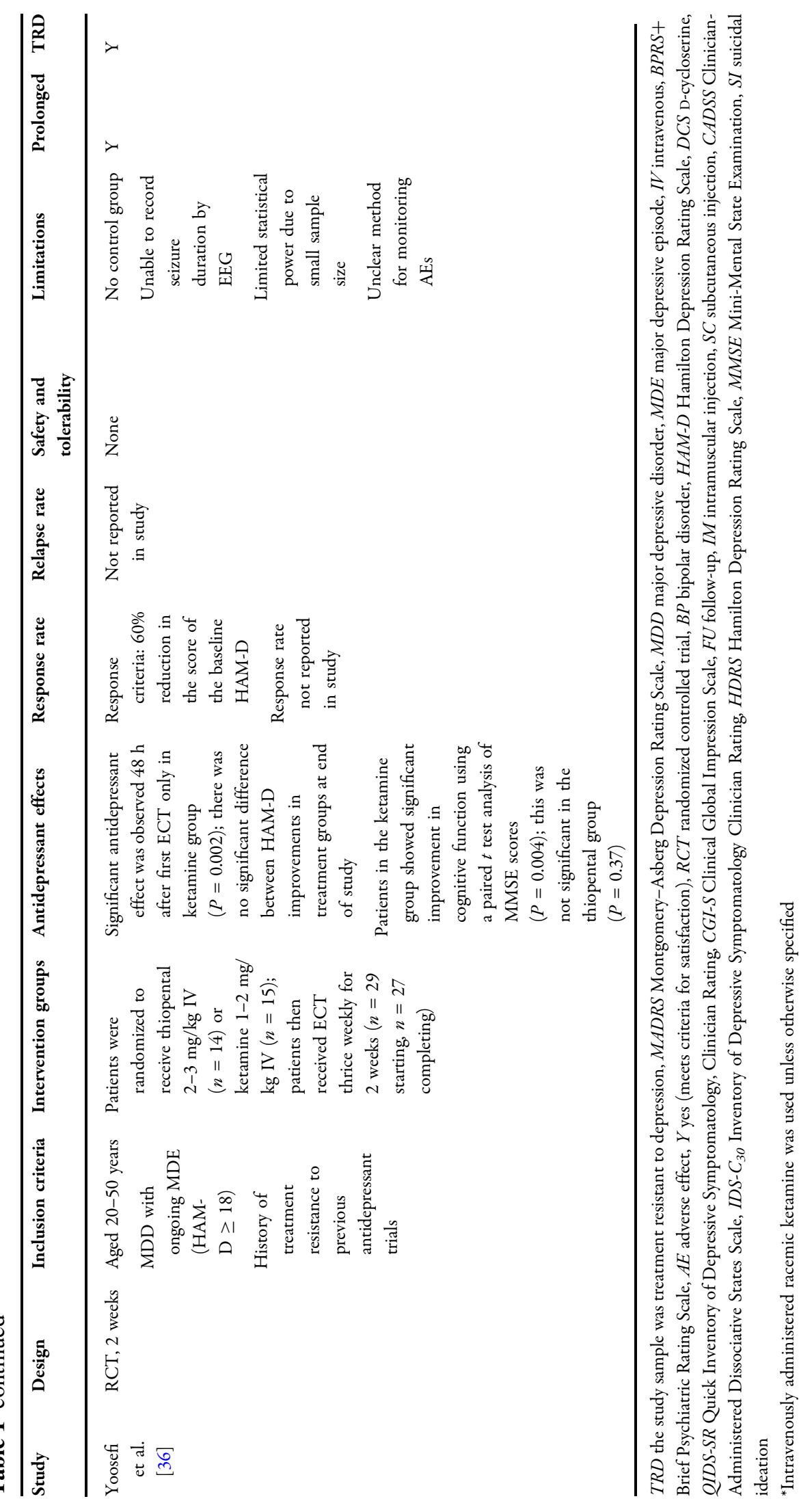


While no other studies were terminated prematurely, similar, non-significant outcomes were observed in some studies, including no statistically significant differences in sustained reduction of depression (sustained reduction rate $40 \%$ vs $20 \%)$ in an 8 -week RCT $(n=20)$ by Lenze et al. [35]; no Hamilton Depression Rating Scale (HAM-D) reductions between D-cycloserine (DCS) or placebo in follow-up $(P=0.30)$ in a 6 -week RCT $(n=32)$ by Chen et al. [20]; and no differences between treatment groups in continuing the antidepressant effect of IV ketamine in a 2-week RCT $(n=34)$ by Costi et al. [24].

In a 4 -week RCT $(n=42)$ by Ibrahim et al. [26], no significant improvements in MADRS score were observed between treatment groups after week 4. Moreover, no significant difference in days-to-relapse were observed, with 17.2 and 9.8 days to relapse in the ketamine-riluzole (a single dose of $0.5 \mathrm{mg} / \mathrm{kg}$ IV ketamine then 100-200 mg daily of riluzole) and the ketamine-placebo groups, respectively $(0.5 \mathrm{mg} / \mathrm{kg}$ IV ketamine then placebo once daily).

The response and relapse rate in six studies studying oral agents (i.e., clonidine, D-cycloserine, lamotrigine, lithium, rapamycin, and riluzole) concurrent with IV ketamine were widely reported $(k=5 / 6 \quad[20,26,33-35] ; k=3 / 6$ $[24,26,34]$, respectively). The total mean response rate for oral agents in these RCTs was $56.6 \%(72 / 127)$. Furthermore, the foregoing studies reported a total relapse rate of $64.1 \%$ $(25 / 39)$ at the end of their study durations.

Within the foregoing six studies, the primary aim was to prolong the efficacy of ketamine using an oral agent as continuation therapy. All six oral continuation trials were well tolerated without any significant safety concerns reported. Three trials had no significant reported dissociative effects [20, 26, 35]; however, the remaining three trials [24, 33, 34] did report significant, although mild and transient dissociative effects.

An open-label trial $(n=16)$ by Wilkinson et al. [31] evaluated repeat-dose ketamine infusions of $0.5 \mathrm{mg} / \mathrm{kg}$ (up to four infusions) administered over 2 weeks, concurrent with 12 sessions of CBT over 10 weeks. In this sample all patients were diagnosed with MDD, ongoing major depressive episode (MDE), and treatment resistance, defined as a lack of response to at least two antidepressant trials in their current episode. A significant antidepressant effect was observed following 2 weeks of IV ketamine treatment with $50 \%(8 / 16)$ of patients as responders and $43.8 \%(7 / 16)$ of patients as remitters. For responders $(5 / 8)$, the median time to relapse following ketamine treatment was 12 weeks, whereas nonresponders only had significant improvement in MADRS scores until week 3 and showed no further improvement thereafter. Remitters (3/7) maintained remission until week 4 , with some patients (2/7) maintaining clinical remission until 8 weeks post-ketamine treatment. Responders (2/8) reported a relapse at week 8 post-ketamine treatment. Adverse effects were not recorded in the study [31].

In a smaller RCT $(n=29)$, Yoosefi et al. [36] assessed the efficacy of IV ketamine with thiopental in patients receiving ECT (primary outcome). Patients were randomized to receive either $2-3 \mathrm{mg} / \mathrm{kg}$ of IV thiopental or $1-2 \mathrm{mg} / \mathrm{kg}$ of IV ketamine, followed by thrice weekly ECT for 2 weeks. In patients diagnosed with MDD, a history of treatment resistance to previous antidepressant trials and an ongoing MDE with moderate-to-severe symptoms based on a Hamilton Depression Rating Scale (HDRS) of 18 or higher was associated with significant antidepressant effects within $48 \mathrm{~h}$ of the ECT in only the ketamine group $(P=0.002)$.

It was reported that no significant differences between HAM-D improvements in treatment groups were observed at the end of the study. Subjects in the ketamine group demonstrated significant improvement in cognitive function, as indicated by a paired samples $t$ test analysis of Mini-Mental State Examination (MMSE) scores $(P=0.004)$. Conversely, the improvement in cognitive function as measured by the MMSE scores was not significant in the thiopental group $(P=0.37)$. No adverse effects from either the ketamine or the ECT treatment were reported.

Nine studies ranging in duration from 12 days to 6 weeks analyzed antidepressant effects in IV ketamine monotherapy and time to relapse $[12,13,22,25,27-30,32]$. The included 
patients were diagnosed with MDD and were treatment resistant, defined as a lack of response to varying numbers of antidepressant trials. Of these prospective studies, eight were open-label trials $[12,13,22,25,27,28,30,32]$ and two were RCTs $[29,32]$ with a total of 166 patients receiving repeated ketamine monotherapy. As a result of the disparate dosing intensity as well as frequency of ketamine administration, the mean response rate reported in those that completed all ketamine infusions also varied from $25 \%$ [32] to $92 \%$ [30], both in open-label trials. The total mean response rate for these repeat-ketamine trials was $64.2 \%(95 / 148)$. The reported relapse rate was $77.8 \%(63 / 81)$. Similarly, the mean time until relapse following the final ketamine infusion varied from 16 days [30] to 24 days [34], both in open-label trials. All nine IV ketamine monotherapy trials were reported with good profiles of tolerability and safety, with no significant differences in adverse effects or discontinuation between treatment groups. Moreover, most reported adverse events were transient and mild in dissociation $[12,13,22,25,27,28,30,32]$.

The criteria for response varied within the selected studies; for example, most of the prospective studies (14/18) used the definition of at least $50 \%$ reduction in MADRS scores compared to the baseline or the previous ketamine infusion [12, 13, 21, 22, 26-31, 33-35, 37]. Four studies, all involving up to six repeat-ketamine infusions over a period of 12-14 days, recorded depressive symptoms using MADRS scores $[12,22,28,30]$. The foregoing studies reported similar baseline scores with a mean MADRS baseline score of $30.85 \pm 1$.66. Consequently, MADRS score between these studies improved significantly within $24 \mathrm{~h}$, with aan het Rot et al. [22] reporting $6.9 \pm 2.8$ and Murrough et al. [28] reporting $18.8 \pm 5.5$. At study endpoint, MADRS scores showed further variation observed at $29.7 \pm 6.4,18.9 \pm 6.6$, and $5.4 \pm 3.4$, respectively $[12,22,28]$. Of the trials reporting study endpoint MADRS scores, the duration of ketamine infusions also varied from 40 to over $100 \min [12,22,28]$.

Other studies (4/18) using the HDRS defined response as at least 50\% improvement in HDRS scores $[20,25,32,36]$ (Table 1). Two similar studies, both using repeat ketamine with a study duration of 3 weeks, recorded depressive symptoms using HDRS scores [25, 32]. The two other studies $[25,32]$ included participants with moderate-to-severe symptom severity on the HDRS at baseline (i.e., HDRS scores of $31.6 \pm 5.2$ and $28.6 \pm 4.8$, respectively). The antidepressant effects observed at week 3 did not endure, with each study group reporting relapse rates of $83.3 \%(10 / 12)$ and $80 \%(4 / 5)$, respectively $[25,32]$.

\section{Retrospective Studies Assessing Prolonging Ketamine's Antidepressant Effects for MDD}

Retrospective studies including one chart review (28 cases) [2] and three case reports (with 1-3 cases per article) [38-40] were identified. A total of four patients received psychopharmacological and psychological therapies, and 28 patients received transcranial magnetic stimulation (TMS), to prolong the antidepressant effects of IV ketamine (Table 2). All patients enrolled in the retrospective studies were diagnosed with TRD and reported suicidal ideation $[2,38-40]$. Best et al. [2] reported $(n=28)$ on the efficacy of combination TMS with ketamine (CTK). The course of treatment involved 10-30 sessions of coincident treatment of $0.4-2.3 \mathrm{mg} /$ $\mathrm{kg}$ IV ketamine (20 min) and high-output TMS (30 min). A significant mean reduction in Clinical Global Impression-Severity (CGI-S) following CTK treatment was observed ( $P$ $\leq 0.0001$ ), along with a sustained effect 2 years post-CTK treatment $(\alpha=0.01 ; \quad t=27.36$; $P<0.0001)$. Long-term efficacy was reported with a mean difference in CGI-S scores from baseline to 2 years following completion of treatment of $4.68 \pm 0.47$ [2].

In the three case studies, patients were given repeat-dose ketamine infusions, followed by maintenance ketamine infusions if deemed necessary [38-40]. Overall, IV ketamine infusions were well tolerated and deemed safe [2, 38-40], with significant dissociative effects only reported in one case study [40], and other mild, transient dissociative effects reported in all studies $[2, \quad 38-40]$ (Table 2). The 
antidepressant effects reported by Best et al., demonstrate a promising mean reduction in the CGI-S group value from $6.1 \pm 0.8$ to $1.7 \pm 0.7$ [2]. The prolongation of ketamine's initial antidepressant effect was observed in all four retrospective studies [2, 38-40], with sustained effects varying greatly from 17 days to 2 years with varying adjunct treatment types, dosages, and frequency of dosages [38]. All studies included patients that had TRD, with some patients being unsuccessfully treated previously with upwards of 24 medication trials and 273 ECTs [39].

\section{DISCUSSION}

As part of this systematic review, ten RCTs ( $N=266$ patients receiving ketamine), eight prospective open-label trials $(N=115$ patients receiving ketamine), and four retrospective studies (total $N=34$ patients receiving ketamine) were included, for a total of 415 patients receiving IV ketamine for TRD. The quality of studies varied and were characterized by a lack of control groups, lack of blinding, small sample sizes (i.e., limited generalizability), and heterogenous methodology for ascertaining and recording adverse effects. Many of the RCTs were of moderate to high quality. Taken together, the evidence base is insufficient with respect to concluding that any specific modality of treatment (other than repeat-dose IV ketamine or intranasal esketamine) has demonstrated safety and maintenance efficacy in acute ketamine responders. Numerous themes emanated and surrounded our analysis herein.

The extant literature contains numerous studies that utilize repeat-dose IV ketamine monotherapy as a means of sustaining the antidepressant effects following ketamine infusion. The most effective frequency of $0.5 \mathrm{mg} / \mathrm{kg}$ dosing was deemed to be twice weekly [37]. All studies included in this systematic review were delimited to ketamine in their study protocol, except for Loo et al. [27], and recorded ketamine infusions about two or three times weekly. There remains, however, a lack of sufficient data with respect to IV ketamine dosing intensity and frequency; a priority for future research.
Moreover, preliminary data suggests that neurostimulatory and/or psychotherapeutic strategies may possibly prolong the antidepressant efficacy of ketamine [42, 43]. Regarding psychotherapy which includes but is not limited to modalities like CBT, the initial outcome of the open-label trial by Wilkinson et al. [31] where up to four infusions of IV ketamine over 2 weeks were administered, concurrent with 12 sessions of CBT over 10 weeks, produced a median relapse time of 12 weeks in the initial responders to ketamine and offered some degree of symptomatic benefit. The lack of control group, however, precludes decisive conclusions on the adjunctive effects of ketamine and CBT.

Best et al. [2] reported that rTMS combined with ketamine resulted in a sustained reduction of CGI severity for up to two years. TMS was well tolerated with no treatment-limiting adverse outcomes from this neurostimulation throughout their study $[2,42]$. It was also reported that ECT was well tolerated with a suggestion of greater efficacy in combination with ketamine. The foregoing benefit was not limited by significant cognitive impairment [36, 38, 39].

Another theme that arose from the current systematic review was the absence of studies evaluating whether oral agents could prolong the antidepressant effects of IV ketamine. Oral agents tested were clonidine [35], D-cycloserine [20], lamotrigine [34], lithium [24], rapamycin [33], and riluzole [26, 34], many of which had significant limitations within their study protocol [35]. It is also reported that lithium dosed to achieve higher peripheral levels may provide a more robust and/or more sustained antidepressant effect [24]. The overall response and relapse rates (i.e., $59.1 \%$ and $64.1 \%$, respectively) do not appear significantly different from what is reported from repeat-dose IV ketamine monotherapy (i.e., $64.2 \%$ and $77.8 \%$, respectively).

There are several methodological aspects that affect inferences and interpretations of our findings. The overarching limitation is the lack of large, replicated, rigorous, randomized control trials with well-characterized populations and standardized outcome measures. A second major limitation is the heterogeneity of populations that were studied as well as lack of sufficient data with respect to patient 
Table 2 Summary of retrospective studies, including case series and case reports on prolonging ketamine treatment

\begin{tabular}{|c|c|c|c|c|c|}
\hline Study & $\begin{array}{l}\text { No. } \\
\text { of } \\
\text { cases }\end{array}$ & Dose and duration & Description & Prolonged & TRD \\
\hline $\begin{array}{l}\text { Best et al. } \\
{[2]}\end{array}$ & 28 & $\begin{array}{l}\text { Frequency of treatment was dependent on } \\
\text { patient responsiveness (10-30 sessions) } \\
\text { CTK included pre-treatment with rTMS, } \\
\text { ketamine } 0.4-2.3 \mathrm{mg} / \mathrm{kg} \text { IV until patient } \\
\text { stiffened, and then TMS was administered }\end{array}$ & $\begin{array}{l}\text { Chart review of patients with TRD who } \\
\text { received combination therapy with TMS } \\
\text { and ketamine (CTK) to determine the } \\
\text { efficacy of the combined antidepressant } \\
\text { therapies. A significant mean reduction in } \\
\text { CGI severity following CTK treatment } \\
\text { completion was observed }(P \leq 0.0001) \text {. } \\
\text { This reduction was sustained for } 2 \text { years } \\
\text { following treatment completion } \\
(P \leq 0.0001) \text {. CTK allowed for greater } \\
\text { TMS intensities than would otherwise be } \\
\text { tolerated. CTK was well tolerated, with no } \\
\text { treatment-limiting adverse outcomes } \\
\text { throughout the study }\end{array}$ & $\mathrm{Y}$ & $\mathrm{Y}$ \\
\hline $\begin{array}{l}\text { Messer et al. } \\
{[38]}\end{array}$ & 2 & $\begin{array}{l}\text { Patient A: } 6 \text { doses of ketamine } 0.5 \mathrm{mg} / \mathrm{kg} \text { IV } \\
\text { (on days } 1,3,5,7,9,11 \text { ) } \\
\text { Patient B: } 2 \text { doses of } 0.5 \mathrm{mg} / \mathrm{kg} \text { IV (on days } \\
1,7 \text { ) and } 4 \text { saline infusions (on days } 3,5,9 \text {, } \\
\text { 11) }\end{array}$ & $\begin{array}{l}\text { A } 50 \text {-year-old man with a history of } \\
\text { depression and concomitant suicidal } \\
\text { ideation with comorbid sleep apnea and } \\
\text { obesity was treated with } 11 \text { medication } \\
\text { trials and seven right unilateral ECTs and } \\
\text { reported no change in mood. He received } \\
\text { six doses of ketamine intravenously every } \\
\text { other day during a 12-day period. He } \\
\text { achieved a sustained clinical response } \\
\text { (BDI } \leq 18 \text { ) on day } 4 \text { with only mild, } \\
\text { transient adverse effects; his response } \\
\text { lasted until day } 39 \text {. Repeated treatments of } \\
\text { ketamine every other day for } 12 \text { days } \\
\text { produced sustained remission of his } \\
\text { depressive symptoms } \\
\text { A } 45 \text {-year-old man with a history of } \\
\text { treatment-resistant major depressive } \\
\text { disorder with comorbid hypertension was } \\
\text { treated with } 9 \text { medication trials and } 105 \\
\text { ECT treatments, producing short-term and } \\
\text { long-term memory loss, and an incomplete } \\
\text { recovery from depression. He also received } \\
\text { implantation of a vagal nerve stimulator } \\
5 \text { years prior. He received two doses of } \\
\text { ketamine intravenously on days } 1 \text { and } 7 \\
\text { within the } 12 \text {-day period, and saline } \\
\text { on days } 3 \text {, } 5 \text {, } 9 \text {, and } 11 \text {. His MMSE score } \\
\text { was } 30 \text { at baseline. He achieved a sustained } \\
\text { clinical response (BDI } \leq 18 \text { ) on day } 2 \\
\text { with only mild, transient adverse effects; } \\
\text { his response lasted until day } 24 \text {. Repeated } \\
\text { treatments of ketamine twice produced } \\
\text { sustained remission of his depressive } \\
\text { symptoms }\end{array}$ & $\mathrm{Y}$ & $\mathrm{Y}$ \\
\hline
\end{tabular}


Table 2 continued

\begin{tabular}{lll}
\hline Study & $\begin{array}{l}\text { No. } \\
\text { of } \\
\text { cases }\end{array}$ & Dose and duration \\
\hline $\begin{array}{c}\text { Messer et al. } \\
{[39]}\end{array}$ & 1 & $\begin{array}{l}\text { Three doses of ketamine } 0.5 \mathrm{mg} / \mathrm{kg} \mathrm{IV} \text { every } \\
\text { other day for } 5 \text { days, followed by } 3 \text { series } \\
\text { of } 6 \text { doses of ketamine } 0.5 \mathrm{mg} / \mathrm{kg} \text { IV given } \\
\text { over } 16 \text { weeks, followed by a maintenance } \\
\text { dose of ketamine } 0.5 \mathrm{mg} / \mathrm{kg} \mathrm{IV} \mathrm{given} \mathrm{every} \\
\text { 3 weeks over } 15 \text { months }\end{array}$ \\
\end{tabular}

Szymkowicz 3 Up to 6 doses of ketamine $0.5 \mathrm{mg} / \mathrm{kg} \mathrm{IV}$ et al. [40] with doses occurring every other day followed by an individualized maintenance dose of ketamine $0.5 \mathrm{mg} / \mathrm{kg} \mathrm{IV}$
A 46-year-old woman with a history of Y treatment-resistant major depressive disorder was treated with 24 medication trials and 273 ECT treatments, producing short-term and long-term memory loss and an incomplete recovery from depression. All interventions have produced only short-lived remission. Her long-term use of ECT caused significant problems with memory loss and focused attention. She received ketamine $0.5 \mathrm{mg} /$ $\mathrm{kg}$ IV which led to a dramatic improvement in her depressive symptoms (DBI 22 to 6). She then received three additional infusions every other day for 5 days. This produced a remission lasting for 17 days after the last infusion. Three series of six infusions were given on alternating business days over the following 16 weeks. These three series produced remissions lasting 16,28 , and 16 days, respectively. A maintenance dose of ketamine $0.5 \mathrm{mg} / \mathrm{kg}$ IV was then established at a 3-week inter-dose interval. She then remained in remission for $>15$ months with only mild, transient adverse effects typical of ketamine

Three cases of TRD with suicide ideation are reported in which repeated doses of ketamine IV were provided. The first patient had rapid and moderately sustained depression symptom relief $4 \mathrm{~h}$ post-infusion 1 (MADRS $\leq 8$ ). The second patient only achieved MADRS scores of a moderate level of depression $4 \mathrm{~h}$ post-infusion 4 . The third patient also only achieved MADRS scores of a moderate level of depression $4 \mathrm{~h}$ postinfusion 4; however, significant functional improvement was observed. The total number of ketamine treatments varied from 16,34 , and 32 , respectively. Dissociative effects of worsened cognitive difficulties and insomnia post-ketamine treatment in patient 2; however, no other adverse effects were noted

TRD the study sample was treatment resistant to depression, $r T M S$ repetitive transcranial magnetic stimulation, TMS transcranial magnetic stimulation, CGI the Clinical Global Impression Scale, $Y$ yes (meets criteria for satisfaction), ECT electroconvulsive therapy, BDI Beck Depression Inventory, MMSE Mini-Mental State Examination, MADRS Montgomery-Asberg Depression Rating Scale *Intravenously administered racemic ketamine was used unless otherwise specified 
characteristics and the degree of treatment resistance/prior longitudinal course before study entry [4]. Additional limitations include but are not limited to the absence of a traditional trial design that would re-randomize "enriched acute responders" with appropriate survival statistics.

\section{CONCLUSIONS}

These results indicate that repeat-dose ketamine monotherapy, albeit insufficiently studied with RCT and placebo, does demonstrate efficacy prolongation in persons with TRD who initially respond to IV ketamine. Moreover, ECT, CBT, and rapamycin concurrent with ketamine treatment for patients with TRD also demonstrate preliminary evidence of efficacy. Most oral agents (i.e., clonidine, D-cycloserine, lamotrigine, lithium, and riluzole) studied concurrently or following a single ketamine infusion were not found to have significant effect in prolonging efficacy in adults with TRD.

Repeat-dose IV ketamine has demonstrated preliminary evidence for maintaining efficacy, and RCT evidence supports repeat-dose esketamine as a maintenance treatment strategy in TRD (this review focused primarily on ketamine rather than esketamine) [20]. Intravenous ketamine treatment for TRD still remains a safe and tolerable short-term intervention; however, further large-scale research is needed on the long-term efficacy and safety of ketamine within this patient population [20].

\section{ACKNOWLEDGEMENTS}

Funding. The authors have received no funding for writing this review. No funding or sponsorship was received for the publication of this article.

Authorship. All named authors meet the International Committee of Medical Journal Editors (ICMJE) criteria for authorship for this article, take responsibility for the integrity of the work as a whole, and have given their approval for this version to be published.

Authors' Contributions. Eric P. McMullen: data curation, investigation, project administration, visualization, writing - original draft. Yena Lee: writing - review and editing. Orly Lipsitz: writing - review and editing. Leanna M.W. Lui: writing - review and editing. Maj Vinberg: writing - review and editing. Roger Ho: writing review and editing. Nelson B. Rodrigues: writing - review and editing. Joshua D. Rosenblat: writing - review and editing. Bing Cao: writing review and editing. Hartej Gill: writing - review and editing. Kayla M. Teopiz: writing - review and editing. Danielle S. Cha: writing - review and editing. Roger S. McIntyre: conceptualization, project administration, visualization, supervision, writing - review and editing.

Disclosures. Dr. Roger McIntyre has received research grant support from CIHR/ GACD/Chinese National Natural Research Foundation; speaker/consultation fees from Lundbeck, Janssen, Purdue, Pfizer, Otsuka, Allergan, Takeda, Neurocrine, Sunovion, Minerva, Intra-Cellular, Abbvie, and Eisai. Dr. Roger McIntyre is a shareholder and CEO of Champignon Brands, Inc. Dr Roger McIntyre is also a member of the journal's Editorial Board. Dr. Joshua Rosenblat has received research grant support from the Canadian Cancer Society, Canadian Psychiatric Association, American Psychiatric Association, American Society of Psychopharmacology, University of Toronto, University Health Network Centre for Mental Health, Joseph M. West Family Memorial Fund and Timeposters Fellowship and industry funding for speaker/consultation/research fees from Janssen, Allergan, Lundbeck, Sunovion and COMPASS. He is the medical director of a private clinic providing intravenous ketamine infusions and intranasal esketamine for depression. Dr. Rosenblat has received research grant support from the Canadian Cancer Society, Canadian Psychiatric Association, American Psychiatric Association, American Society of Psychopharmacology, University of Toronto, University Health Network Centre for Mental Health, Joseph M. West Family Memorial Fund 
and Timeposters Fellowship and industry funding for speaker/consultation/research fees from Janssen, Allergan, Lundbeck, Sunovion and COMPASS. He is the medical director of a private clinic providing intravenous ketamine infusions and intranasal esketamine for depression. Dr. Maj Vinberg has received consultancy fees from Lundbeck, Sunovion and Janssen/Cilag within the last three years. Dr. Danielle Cha reports receiving royalties from Oxford University Press and Cambridge University Press outside the submitted work. Dr. Cha has also received honoraria from Lundbeck outside the submitted work. Eric McMullen, Yena Lee, Orly Lipsitz, Leanna Lui, Roger Ho, Nelson Rodrigues, Bing Cao, Hartej Gill and Kayla Teopiz have have no disclosures to make.

Compliance with Ethics Guidelines. This article is based on previously conducted studies and does not contain any new studies with human participants or animals performed by any of the authors.

Data Availability. All data generated or analyzed during this study are included in this published article/as supplementary information files.

Open Access. This article is licensed under a Creative Commons Attribution-NonCommercial 4.0 International License, which permits any non-commercial use, sharing, adaptation, distribution and reproduction in any medium or format, as long as you give appropriate credit to the original author(s) and the source, provide a link to the Creative Commons licence, and indicate if changes were made. The images or other third party material in this article are included in the article's Creative Commons licence, unless indicated otherwise in a credit line to the material. If material is not included in the article's Creative Commons licence and your intended use is not permitted by statutory regulation or exceeds the permitted use, you will need to obtain permission directly from the copyright holder. To view a copy of this licence, visit http:// creativecommons.org/licenses/by-nc/4.0/.

\section{REFERENCES}

1. Nestler E, Gould E, Manji H. Preclinical models: status of basic research in depression. Biol Psychiat. 2002;52(6):503-28. https://doi.org/10.1016/S00063223(02)01405-1.

2. Best S, Pavel D, Haustrup N. Combination therapy with transcranial magnetic stimulation and ketamine for treatment-resistant depression: a longterm retrospective review of clinical use. Heliyon. 2019;5(8):e02187. https://doi.org/10.1016/j. heliyon.2019.e02187.

3. McIntyre R, Filteau M, Martin L, et al. Treatmentresistant depression: definitions, review of the evidence, and algorithmic approach. J Affect Disord. 2014;156:1-7. https://doi.org/10.1016/j.jad.2013. 10.043 .

4. Gaynes B, Warden D, Trivedi M, Wisniewski S, Fava M, Rush A. What did STAR*D teach us? Results from a large-scale, practical, clinical trial for patients with depression. Psychiatr Serv. 2009;60(11):1439-45. https://doi.org/10.1176/ps.2009.60.11.1439.

5. Stassen H, Delini-Stula A, Angst J. Time course of improvement under antidepressant treatment: a survival-analytical approach. Eur Neuropsychopharmacol. 1993;3(2):127-35. https://doi.org/ 10.1016/0924-977X(93)90264-M.

6. Machado-Vieira R, Baumann J, Wheeler-Castillo C, et al. The timing of antidepressant effects: a comparison of diverse pharmacological and somatic treatments. Pharmaceuticals. 2010;3(1):19-41. https://doi.org/10.3390/ph3010019.

7. Zanos P, Moaddel R, Morris P, et al. Ketamine and ketamine metabolite pharmacology: insights into therapeutic mechanisms. Pharmacol Rev. 2018;70(3):621-60. https://doi.org/10.1124/pr.117. 015198.

8. Leal G, Bandeira I, Correia-Melo F, et al. Intravenous arketamine for treatment-resistant depression: open-label pilot study. Eur Arch Psychiatry Clin Neurosci. 2020. https://doi.org/10.1007/ s00406-020-01110-5.

9. McIntyre R, Carvalho I, Lui L, et al. The effect of intravenous, intranasal, and oral ketamine in mood disorders: a meta-analysis. J Affect Disord. 2020;276:576-84. https://doi.org/10.1016/j.jad. 2020.06.050.

10. Xiong J, Lipsitz O, Chen-Li D, et al. The acute antisuicidal effects of single-dose intravenous ketamine and intranasal esketamine in individuals with major depression and bipolar disorders: a systematic review and meta-analysis. J Psychiatr Res. 
2021;134:57-68. jpsychires.2020.12.038.

https://doi.org/10.1016/j.

11. Marcantoni W, Akoumba B, Wassef $\mathrm{M}$, et al. A systematic review and meta-analysis of the efficacy of intravenous ketamine infusion for treatment resistant depression: January 2009-January 2019. J Affect Disord. 2020;277:831-41. https://doi.org/ 10.1016/j.jad.2020.09.007.

12. Vande Voort J, Morgan R, Kung S, et al. Continuation phase intravenous ketamine in adults with treatment-resistant depression. J Affect Disord. 2016;206:300-4. https://doi.org/10.1016/j.jad. 2016.09.008.

13. Rasmussen K, Lineberry T, Galardy C, et al. Serial infusions of low-dose ketamine for major depression. J Psychopharmacol. 2013;27(5):444-50. https://doi.org/10.1177/0269881113478283.

14. Cooper M, Rosenblat J, Cha D, Lee Y, Kakar R, McIntyre R. Strategies to mitigate dissociative and psychotomimetic effects of ketamine in the treatment of major depressive episodes: a narrative review. World J Biol Psychiatry. 2016;18(6):410-23. https://doi.org/10.3109/15622975.2016.1139747.

15. Lipsitz O, McIntyre R, Rodrigues N, et al. Early symptomatic improvements as a predictor of response to repeated-dose intravenous ketamine: results from the Canadian Rapid Treatment Center of Excellence. Prog Neuropsychopharmacol Biol Psychiatry. 2021;105:110126. https://doi.org/10. 1016/j.pnpbp.2020.110126.

16. Wan L, Levitch C, Perez A, et al. Ketamine safety and tolerability in clinical trials for treatment-resistant depression. J Clin Psychiatry. 2014;76(03): 247-52. https://doi.org/10.4088/JCP.13m08852.

17. Rodrigues N, McIntyre R, Lipsitz O, et al. Safety and tolerability of IV ketamine in adults with major depressive or bipolar disorder: results from the Canadian rapid treatment center of excellence. Expert Opin Drug Saf. 2020;19(8):1031-40. https:// doi.org/10.1080/14740338.2020.1776699.

18. Lipsitz O, Di Vincenzo J, Rodrigues N, et al. Safety, tolerability, and real-world effectiveness of intravenous ketamine in older adults with treatmentresistant depression: a case series. Am J Geriatr Psychiatry. 2021. https://doi.org/10.1016/j.jagp. 2020.12.032.

19. Ng J, Lui L, Rosenblat J, et al. Ketamine-induced urological toxicity: potential mechanisms and translation for adults with mood disorders receiving ketamine treatment. Psychopharmacology. 2021. https://doi.org/10.1007/s00213-021-05767-1.
20. Daly E, Trivedi M, Janik A, et al. Efficacy of esketamine nasal spray plus oral antidepressant treatment for relapse prevention in patients with treatment-resistant depression. JAMA Psychiat. 2019;76(9):893. https://doi.org/10.1001/ jamapsychiatry.2019.1189.

21. Schwartz J, Murrough J, Iosifescu D. Ketamine for treatment-resistant depression: recent developments and clinical applications. Evid Based Ment Health. 2016;19(2):35-8. https://doi.org/10.1136/ eb-2016-102355.

22. aan het Rot M, Collins K, Murrough J, et al. Safety and efficacy of repeated-dose intravenous ketamine for treatment-resistant depression. Biol Psychiatry. 2010;67(2):139-45. https://doi.org/10.1016/j. biopsych.2009.08.038.

23. Chen M, Cheng C, Gueorguieva R, et al. Maintenance of antidepressant and antisuicidal effects by D-cycloserine among patients with treatment-resistant depression who responded to low-dose ketamine infusion: a double-blind randomized placebo-control study. Neuropsychopharmacology. 2019;44(12):2112-8. https://doi.org/10.1038/ s41386-019-0480-y.

24. Costi S, Soleimani L, Glasgow A, et al. Lithium continuation therapy following ketamine in patients with treatment resistant unipolar depression: a randomized controlled trial. Neuropsychopharmacology. 2019;44(10):1812-9. https:// doi.org/10.1038/s41386-019-0365-0.

25. Cusin C, Ionescu D, Pavone K, et al. Ketamine augmentation for outpatients with treatment-resistant depression: preliminary evidence for twostep intravenous dose escalation. Aust N Z J Psychiatry. 2016;51(1):55-64. https://doi.org/10.1177/ 0004867416631828 .

26. Ibrahim L, DiazGranados N, Franco-Chaves J, et al. Course of improvement in depressive symptoms to a single intravenous infusion of ketamine vs add-on Riluzole: results from a 4 -week, double-blind, placebo-controlled study. Neuropsychopharmacology. 2012;37(6):1526-33. https://doi.org/10.1038/npp. 2011.338 .

27. Loo C, Gálvez V, O'Keefe E, et al. Placebo-controlled pilot trial testing dose titration and intravenous, intramuscular and subcutaneous routes for ketamine in depression. Acta Psychiatr Scand. 2016;134(1):48-56. https://doi.org/10.1111/acps. 12572 .

28. Murrough J, Perez A, Pillemer S, et al. Rapid and longer-term antidepressant effects of repeated ketamine infusions in treatment-resistant major depression. Biol Psychiatry. 2013;74(4):250-6. https://doi.org/10.1016/j.biopsych.2012.06.022. 
29. Phillips J, Norris S, Talbot J, et al. Single, repeated, and maintenance ketamine infusions for treatmentresistant depression: a randomized controlled trial. Am J Psychiatry. 2019;176(5):401-9. https://doi. org/10.1176/appi.ajp.2018.18070834.

30. Shiroma P, Johns B, Kuskowski M, et al. Augmentation of response and remission to serial intravenous subanesthetic ketamine in treatment resistant depression. J Affect Disord. 2014;155: 123-9. https://doi.org/10.1016/j.jad.2013.10.036.

31. Wilkinson S, Wright D, Fasula M, et al. Cognitive behavior therapy may sustain antidepressant effects of intravenous ketamine in treatment-resistant depression. Psychother Psychosom. 2017;86(3): 162-7. https://doi.org/10.1159/000457960.

32. Ionescu D, Bentley K, Eikermann M, et al. Repeat dose ketamine augmentation for treatment-resistant depression with chronic suicidal ideation: a randomized, double blind, placebo controlled trial. J Affect Disord. 2019;243:516-24. https://doi.org/ 10.1016/j.jad.2018.09.037.

33. Abdallah C, Averill L, Gueorguieva R, et al. Modulation of the antidepressant effects of ketamine by the mTORC1 inhibitor rapamycin. Neuropsychopharmacology. 2020;45(6):990-7. https://doi. org/10.1038/s41386-020-0644-9.

34. Mathew S, Murrough J, aan het Rot M, Collins K, Reich D, Charney D. Riluzole for relapse prevention following intravenous ketamine in treatment-resistant depression: a pilot randomized, placebo-controlled continuation trial. Int J Neuropsychopharmacol. 2010;13(1):71-82. https:// doi.org/10.1017/S1461145709000169.

35. Lenze E, Farber N, Kharasch E, et al. Ninety-six hour ketamine infusion with co-administered clonidine for treatment-resistant depression: a pilot randomised controlled trial. World J Biol Psychiatry. 2016;17(3):230-8. 15622975.2016.1142607.

36. Yoosefi A, Sepehri A, Kargar M, et al. Comparing effects of ketamine and thiopental administration during electroconvulsive therapy in patients with major depressive disorder. J ECT. 2014;30(1):15-21. https://doi.org/10.1097/yct.0b013e3182a4b4c6.
37. Singh J, Fedgchin M, Daly E, et al. A double-blind, randomized, placebo-controlled, dose-frequency study of intravenous ketamine in patients with treatment-resistant depression. Am J Psychiatry. 2016;173(8):816-26. https://doi.org/10.1176/appi. ajp.2016.16010037.

38. Messer M, Haller I, Larson P, Pattison-Crisostomo J, Gessert C. The use of a series of ketamine infusions in two patients with treatment-resistant depression. J Neuropsychiatry Clin Neurosci. 2010;22(4):442-4. https://doi.org/10.1176/jnp.2010.22.4.442.

39. Messer M, Haller I. Maintenance ketamine treatment produces long-term recovery from depression. Primary Psychiatry. 2010;17(4):48-50. https:// sa1s3.patientpop.com/assets/docs/55882.pdf

40. Szymkowicz S, Finnegan N, Dale R. A 12-month naturalistic observation of three patients receiving repeat intravenous ketamine infusions for their treatment-resistant depression. J Affect Disord. 2013;147(1-3):416-20. https://doi.org/10.1016/j. jad.2012.10.015.

41. Fava M, Freeman M, Flynn M, et al. Double-blind, placebo-controlled, dose-ranging trial of intravenous ketamine as adjunctive therapy in treatment-resistant depression (TRD). Mol Psychiatry. 2018;25(7):1592-603. https://doi.org/10.1038/ s41380-018-0256-5.

42. Pradhan B, Parikh T, Makani R, Sahoo M. Ketamine, transcranial magnetic stimulation, and depression specific yoga and mindfulness based cognitive therapy in management of treatment resistant depression: review and some data on efficacy. Depress Res Treat. 2015;2015:1-14. https://doi.org/ $10.1155 / 2015 / 842817$.

43. McIntyre RS, Rosenblat JD, Nemeroff CB, Sanacora G, Murrough JW, Berk M, Brietzke E, Dodd S, Gorwood P, Ho R, Iosifescu DV, Lopez Jaramillo C, Kasper S, Kratiuk K, Lee JG, Lee Y, Lui LMW, Mansur RB, Papakostas GI, Subramaniapillai M, Thase M, Vieta E, Young AH, Zarate CA Jr, Stahl S (2021) Synthesizing the evidence for ketamine and esketamine in treatment-resistant depression: an international expert opinion on the available evidence and implementation. Am J Psychiatry. https://doi. org/10.1176/appi.ajp.2020.20081251. 